\title{
Depressed Baroreflex Sensitivity in Hypertensive Rats: A Role for Reactive Oxygen Species
}

\section{Drielle D Guimaraes and Valdir A Braga*}

Biotechnology Center, Federal University of Paraiba, Joao Pessoa, PB, Brazil

Reactive oxygen species (ROS) play an important role in the development and maintenance of cardiovascular diseases including hypertension and heart failure. In special, the relationship between oxidative stress and hypertension has been demonstrated in several models of experimental hypertension. For instance, increased ROS formation precedes the development of hypertension in spontaneously hypertensive rats and in renovascular hypertensive mice [1-3].

One of the key mechanisms in controlling blood pressure in health and disease is the baroreflex. Baroreceptors located in the carotid sinuses and aortic arch detect changes in blood pressure and trigger reflex autonomic adjustments that buffer alterations in blood pressure. In pathological conditions such as hypertension, there is impairment in the autonomic control of blood pressure resulting in changes in baroreflex sensitivity [4-6]. Indeed, compelling evidence show that the baroreflex modulation of heart rate is impaired in spontaneously hypertensive rats and patients with primary hypertension [6,7]. We have recently demonstrated that acute antioxidant therapy improves baroreflex sensitivity in models of primary (essential) and secondary hypertension $[5,6]$.

In a model of renovascular hypertension, the 2-kidney-1-clip (2K1C), we have shown that acute treatment with Vitamin C (150 $\mathrm{mg} / \mathrm{Kg}$, i.v.), a well-known antioxidant, restored the depressed baroreflex sensitivity in those hypertensive animals [5]. Furthermore, administration of apocynin $(30 \mu \mathrm{g} / \mathrm{Kg}$, i.v. $)$, a NADPH oxidase inhibitor, improved baroreflex sensitivity in the $2 \mathrm{~K} 1 \mathrm{C}$ group. In the same study, autonomic blockade with either methylatropine or propranolol reduced the changes in heart rate to the same extent in normotensive and hypertensive groups suggesting that improved baroreflex sensitivity by antioxidants were mediated by improvement in autonomic function. Taken together, those data suggest that NADPH oxidase-derived reactive oxygen species are involved in the blunted baroreflex sensitivity in secondary hypertension and that acute scavenging of superoxide restores baroreflex sensitivity. Regarding primary hypertension, we have also demonstrated in spontaneously hypertensive rats that acute scavenging of superoxide or inhibition of the NADPH oxidase, the main source of ROS in hypertension, improves impaired baroreflex sensitivity and reduces oxidative stress in those animals [6].

The precise site of action where acute antioxidant therapy produces its beneficial effects in order to ameliorate baroreflex sensitivity remains unknown. However, due to the ability of our antioxidant therapy to act beyond the blood brain barrier, it might involve both peripheral and central mechanisms. Those preliminary studies point out to a possible role to antioxidant therapy for improving baroreflex sensitivity in hypertensive patients. Although an interesting possibility, it still awaits further investigation.

\section{References}

1. Kitiyakara C, Wilcox CS (1998) Antioxidants for hypertension. Curr Opin Nephrol Hypertens 7: 531-538.

2. Burmeister MA, Young CN, Braga VA, Butler SD, Sharma RV, et al. (2011) In vivo bioluminescence imaging reveals redox-regulated activator protein-1 activation in paraventricular nucleus of mice with renovascular hypertension Hypertension 57: 289-297.

3. Braga VA, Burmeister MA, Zhou Y, Sharma RV, Davisson RL (2008) Selective ablation of AT1a receptors in rostral ventrolateral medulla (RVLM) prevents chronic angiotensin-II-dependent hypertension in part by reducing oxidant stress in this region. Hypertension 52: e34.

4. Braga VA (2010) Dietary salt enhances angiotensin II-induced superoxide formation in the rostral ventrolateral medulla. Auton Neurosci 155: 14-18.

5. Botelho-Ono MS, Pina HV, Sousa KH, Nunes FC, Medeiros IA, et al. (2011) Acute superoxide scavenging restores depressed baroreflex sensitivity in renovascular hypertensive rats. Auton Neurosci 159: 38-44.

6. Guimaraes DD, Carvalho CC, Braga VA (2012) Scavenging of NADPH Oxidase-derived Superoxide Anions Improves Depressed Baroreflex Sensitivity in Spontaneously Hypertensive Rats. Clin Exp Pharmacol Physiol 39: 373-378.

7. Xing-Sheng Y, Yong-Zhi L, Jie-Xin L, Yu-Qing G, Zhang-Huang C, et al. (2010) Genetic influence on baroreflex sensitivity in normotensive young men. Am J Hypertens 23: 655-659.
*Corresponding author: Valdir A Braga, Director, Department of Biotechnology, Biotechnology Center, Federal University of Paraiba, Joao Pessoa, PB 58051-900, Brazil, Tel: 55833216 7511; Fax: 55833216 7511; E-mail: valdir@cbiotec.ufpb.br

Received March 13, 2012; Accepted March 15, 2012; Published March 18, 2012

Citation: Guimaraes DD, Braga VA (2012) Depressed Baroreflex Sensitivity in Hypertensive Rats: A Role for Reactive Oxygen Species. J Hypertens 1:e103. doi:10.4172/2167-1095.1000e103

Copyright: @ 2012 Guimaraes DD, et al. This is an open-access article distributed under the terms of the Creative Commons Attribution License, which permits unrestricted use, distribution, and reproduction in any medium, provided the original author and source are credited. 